\title{
Giant Cystic Cum Solid Schwannoma of Conus Medullaris: A Rare Case Report and Review of Literature
}

\author{
Sumit Bansal ${ }^{1}$ Ashok Kumar Mahapatra ${ }^{1}$ Pritinanda Mishra ${ }^{2}$ \\ ${ }^{1}$ Department of Neurosurgery, All India Institute of Medical Sciences, \\ Bhubaneswar, Orissa, India \\ 2 Department of Pathology and Laboratory Medicine, All India \\ Institute of Medical Sciences, Bhubaneswar, Orissa, India \\ Address for correspondence Dr Sumit Bansal, MCh, Room No. 419, \\ Department of Neurosurgery, All India Institute of Medical Sciences, \\ Bhubaneswar, Orissa 751019, India \\ (e-mail: drsumitbansal@gmail.com).
}

Indian J Neurosurg 2016;5:63-66.

\begin{abstract}
Keywords

- conus medullaris

- intramedullary tumor

- schwannoma

- resectability

Giant schwannoma of the conus medullaris is a rare form of spinal neoplasm. A 22year-old woman presented with sciatica. Magnetic resonance imaging of the spine showed a mass lesion in the conus medullaris region with nerve compression. Subtotal resection was done and histologic analysis confirmed the diagnosis as Schwannoma. The patient improved in symptoms after surgery. This case report of a very rare cystic tumor is presented with review of the literature.
\end{abstract}

Schwannoma is a benign, slow growing, encapsulated tumor arising from Schwann cells of the nerve sheath. ${ }^{1}$ Intramedullary schwannomas constitute nearly $1.1 \%$ of all the spinal schwannoma and $0.3 \%$ of all intramedullary tumors. $^{2}$ Intramedullary schwannomas in the conus medullaris are extremely rare. They are generally associated with neurofibromatosis (NF) 1 and $2 .^{2}$ We pres-ent a case of intramedullary schwannoma in the conus medullaris, which is very rare, and we reviewed the radiological and surgical features of this case in the context of the existing literature.

A 22-year-old woman was admitted to our department with progressive lower back pain for 1 year. There was no neurologic deficit along with any cutaneous stigmata of NF. Magnetic resonance imaging (MRI) of the lumbar spine revealed a left-sided cystic cum solid contrast-enhancing tumor in the conus medullaris region with nerve compression (-Fig. 1). After L1-3 laminectomy, a midline durotomy was performed and a left-sided, solid cum cystic encapsulated, oval lesion attached to nerve roots was found in the conus medullaris region. Using microsurgical techniques, subtotal excision of tumor was done due to dense adhesion of tumor capsule to nerve

received

September 20, 2015 accepted

November 23, 2015

published online

February 24, 2016 roots. The patient remained neurologically intact after surgery. The postoperative MRI (-Fig. 2) revealed very good decompression of thecal sac with some residual intramedullary component. Histopathology confirmed the diagnosis of Schwannoma (-Fig. 3).

Spinal schwannomas are tumors originating from the Schwann cells; hence their location is usually intradural extramedullary and/or extradural. ${ }^{3}$ Intramedullary spinal schwannomas most commonly occur in the cervical spine (61\%) followed by thoracic (29\%) and lumbar (10\%) spine 4 with rare occurrence at the level of the conus medullaris. Till date only nearly 40 cases of schwannoma of conus medullaris have been reported in the English literature. ${ }^{3}$

Hypotheses regarding the origin of intramedullary schwannomas include (1) ectopic Schwann cells originating from the embryonic neural ridge; (2) Schwann cells ensheathing the aberrant intramedullary nerve fibers; (3) Schwann cells extending along the branches of the anterior spinal artery; (4) neoplastic growth of Schwann cells into the cord from areas where the posterior nerve roots enter the pia mater; and (5) transformation of pial cells of neuroectodermal origin into Schwann cells. ${ }^{5}$
DOI http://dx.doi.org/ 10.1055/s-0036-1572376. ISSN 2277-954X. (c) 2016 Neurological Surgeons' Society of India
License terms

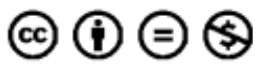




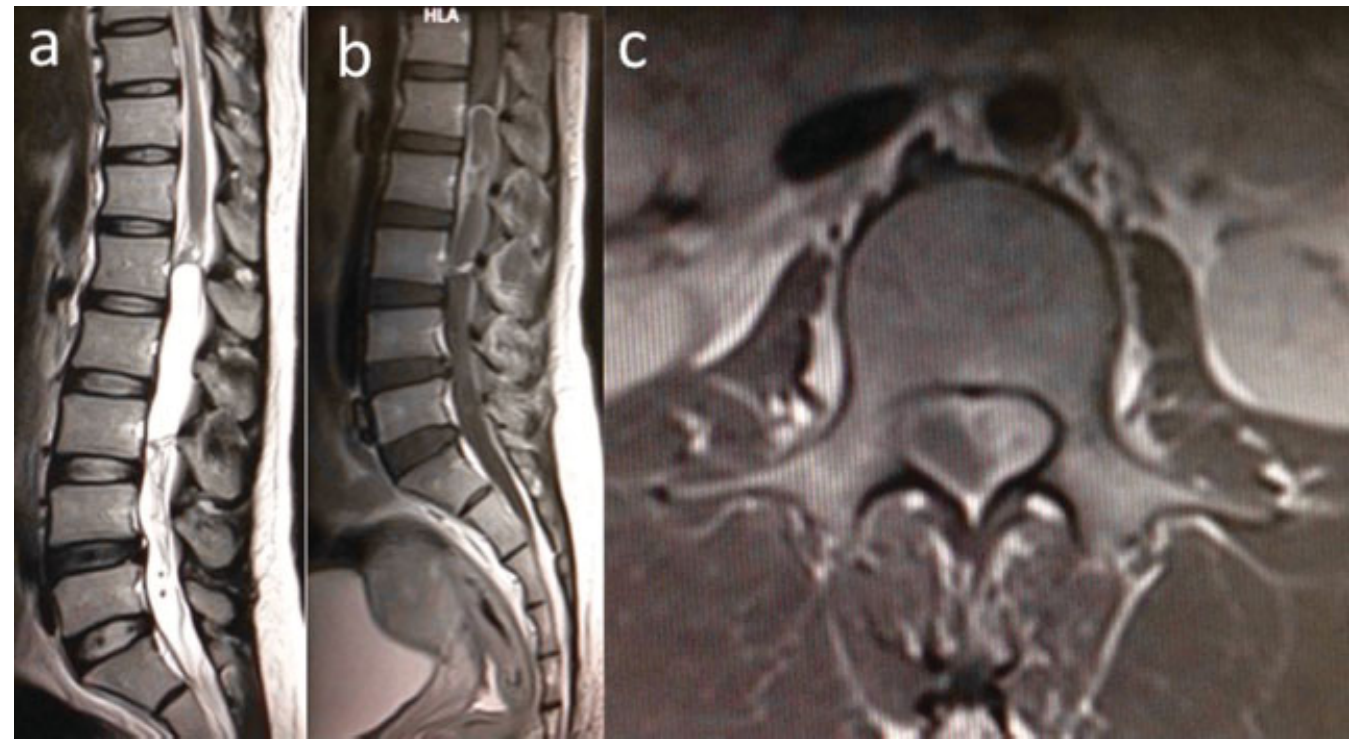

Fig. 1 Preoperative images: Sagittal T2-weighted MRI (a) showing hyperintense tumor in L1-3 region, sagittal (b) and axial (c) T1-weighted images with gadolinium contrast showed homogeneous enhancement of the tumor.

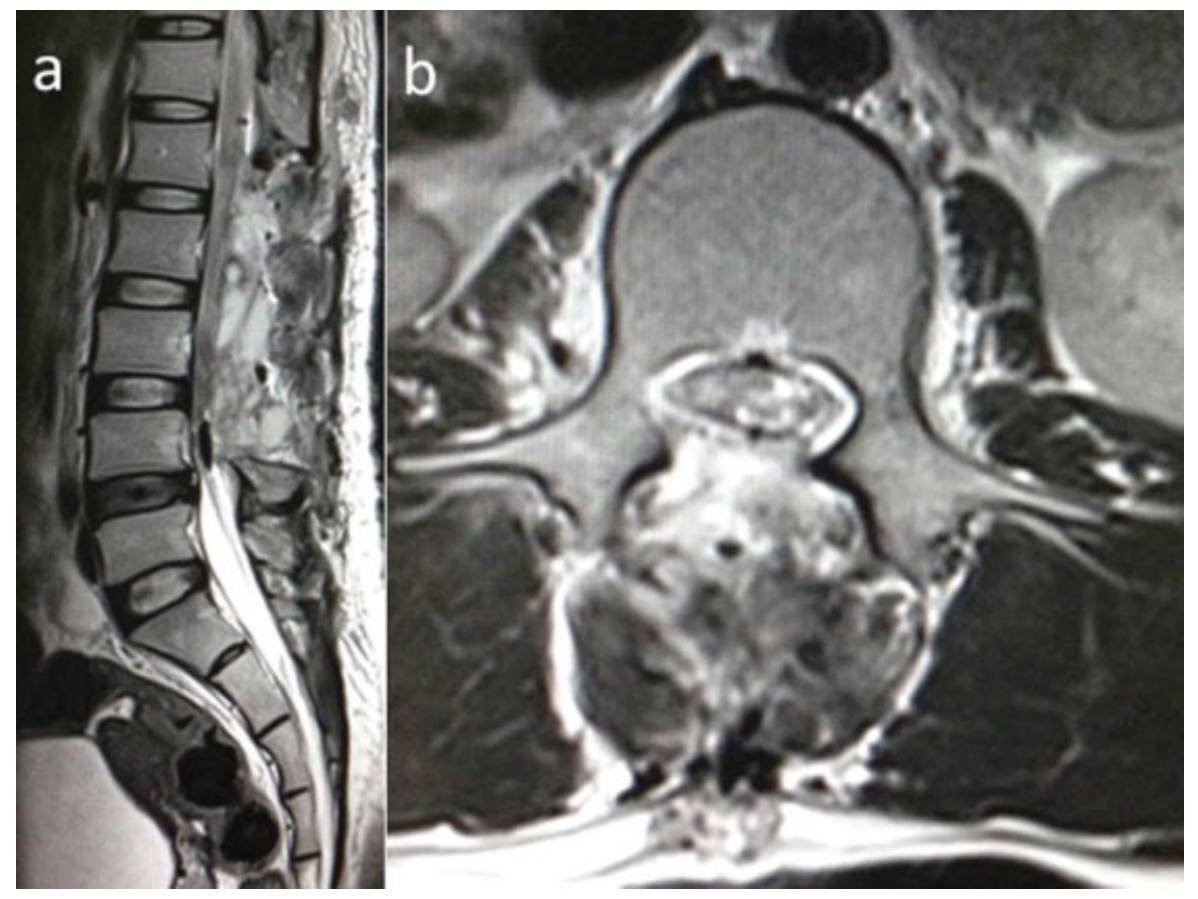

Fig. 2 Postoperative images: sagittal (a) and axial (b) T2-weighted MRI showed good decompression of thecal sac after tumor removal.

The treatment of schwannomas of the conus medullaris consists of surgical excision of the tumor and decompression of the spinal nerves. ${ }^{6}$ Conti et $\mathrm{al}^{5}$ observed recurrence in all cases when the excision was subtotal. However, total resection may be difficult due to adherence of the tumor to the surrounding neural tissue. In these cases, subtotal or near-total removal is a viable option to reduce postoperative deterioration.
In conclusion, complete removal of schwannoma of the conus medullaris is advised to avoid recurrence, but subtotal excision of tumor may be attempted to avoid complications if the tumor has dense adhesions to nerve roots.

Conflict of Interest

None. 


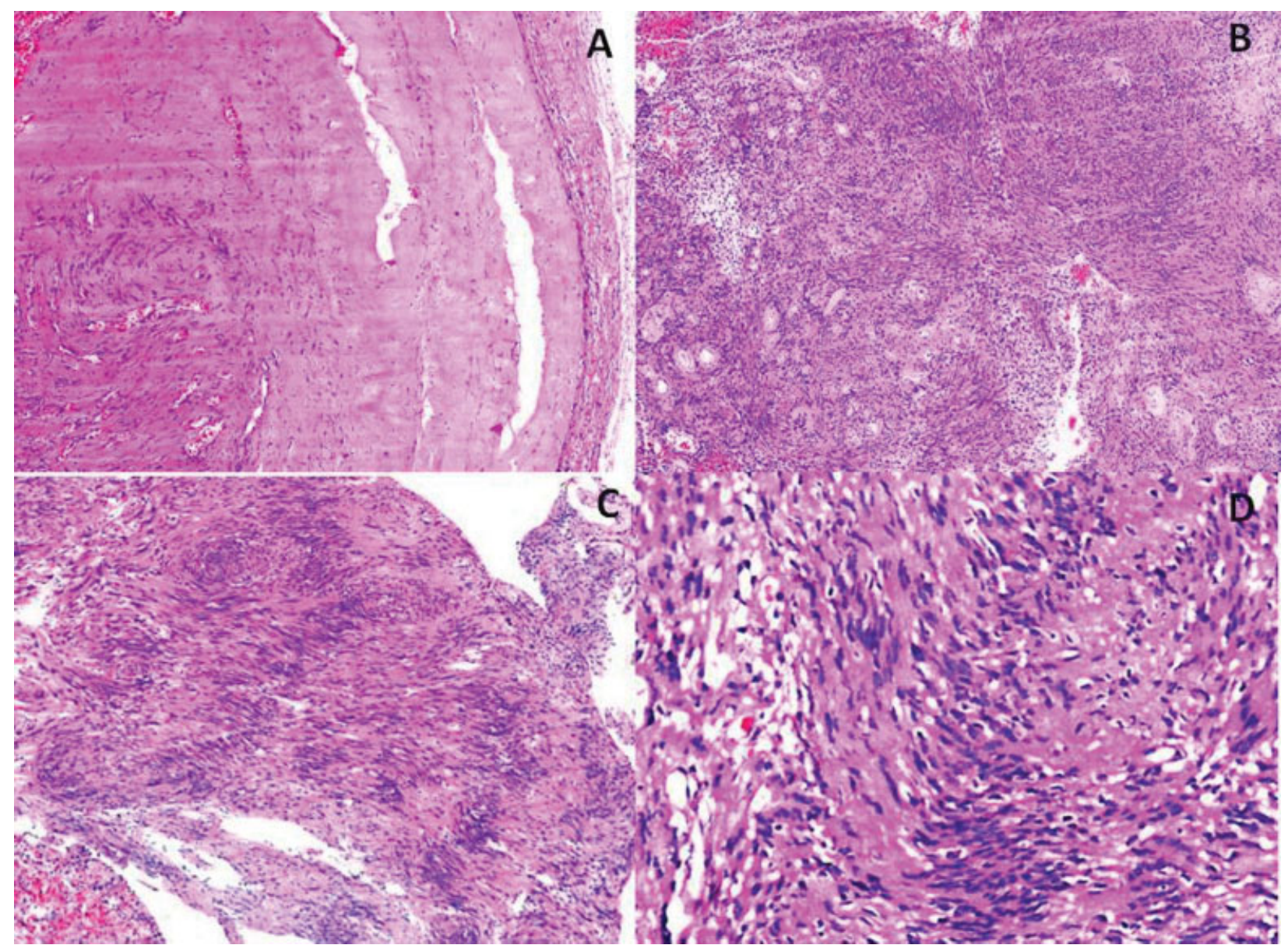

Fig. 3 (A) An encapsulated tumor (H\&E 100X). (B) Antony A areas showing spindle cells in short fascicles and Antony B hypocellular myxoid areas containing hyalinized blood vessels (H\&E 100X). (C) Numerous Verocay bodies seen (H\&E 100X). (D) High-power view showing nuclear palisading and microcystic change (H\&E 400X).

Financial Support

None.

\section{References}

1 Hasegawa M, Fujisawa H, Hayashi Y, Tachibana O, Kida S, Yamashita J. Surgical pathology of spinal schwannomas: a light and electron microscopic analysis of tumor capsules. Neurosurgery $2001 ; 49(6): 1388-1392$, discussion 1392-1393

2 Darwish BS, Balakrishnan V, Maitra R. Intramedullary ancient schwannoma of the cervical spinal cord: case report and review of literature. J Clin Neurosci 2002;9(3):321-323
3 Ohtonari T, Nishihara N, Ota T, Ota S, Koyama T. Intramedullary schwannoma of the conus medullaris complicated by dense adhesion to neural tissue. Neurol Med Chir (Tokyo) 2009;49(11): 536-538

4 Binatli O, Erşahin Y, Korkmaz O, Bayol U. Intramedullary schwannoma of the spinal cord. A case report and review of the literature. J Neurosurg Sci 1999;43(2):163-167, discussion 167-168

5 Conti P, Pansini G, Mouchaty H, Capuano C, Conti R. Spinal neurinomas: retrospective analysis and long-term outcome of 179 consecutively operated cases and review of the literature. Surg Neurol 2004;61(1):34-43,discussion 44

6 Celli P. Treatment of relevant nerve roots involved in nerve sheath tumors: removal or preservation? Neurosurgery 2002; 51(3):684-692, discussion 692 